\title{
Evaluation of Different Bar Materials in Terms of Stress Transmission in All-on-four and All-on-three Concepts: A Three-dimensional Finite Element Analysis
}

\author{
Nurullah Türker
}

\begin{abstract}
Aim: The aim of this study is to evaluate the effects of materials used in bar construction in all-on-four (AOF) and all-on-three (AOT) concepts on stress transmission by three-dimensional (3D) finite element analysis (FEA) method.

Materials and methods: Two models were designed to simulate the AOF and AOT concepts in the mandible. For the AOF concept, the mesial implants were placed at the canine teeth position and the distal implants were inclined $40^{\circ}$ distally, with the neck portions protruding from the second premolar region on both sides. For the AOT concept, one of the implants was placed in the middle of the two incisors in the mandible and the other two implants were placed distally in the first premolar region. Bars and prostheses were designed and the model parts were combined. Four different bar materials were defined after creating four different models for both concepts. A force of $100 \mathrm{~N}$ was applied perpendicular to the long axis of the left first molar tooth from the central fossa. Elastic strain values of bar structures and bone tissue were obtained.

Results: The lowest strain values in both AOF concept and AOT concept were observed in the cobalt-chromium bar structure. In both concepts, the lowest strain values in bone tissue were observed in models produced with type IV gold alloy bars, while the highest strain values were observed in models produced with silver-palladium alloy bars.

Conclusion: In AOF and AOT concepts, the type of bar material affects the strains in the bar structure and bone tissue. The material with the lowest strain observed in the bar material and the material causing the lowest tension in the bone tissue are not the same.

Clinical significance: In the AOF and AOT concepts, which are fixed prosthetic treatment options with a less number of implants, the type of bar material used is important for the success of the treatment.

Keywords: All-on-four, All-on-three, Bar material, Dental implant, Finite element analysis.

International Journal of Experimental Dental Science (2019): 10.5005/jp-journals-10029-1193
\end{abstract}

\section{INTRODUCTION}

The loads to which the prosthesis is exposed are transmitted to the bone tissue through implants. Decreasing the number of implants in fixed prosthetic treatments means that the chewing forces are transmitted to the bone with fewer implants. In such planning, the prosthetic structure has a longer area that is not supported by the implant. In order to prevent the disadvantages of this situation, the prosthetic structure is strengthened by using bar structures in prosthetic treatments. In the presence of a bar, the loads coming to the prosthesis are more evenly distributed over the implants. ${ }^{1,2}$ Various bar materials are available in dentistry and the effect of material differences on stress distribution and durability for some standard bar designs has been previously investigated by several researchers. ${ }^{3,4}$

Malo et al. reported long-term success rates with all-on-four (AOF) concept, which involves a fixed prosthetic treatment design on four implants, and stated that mechanical complications were low in the AOF concept. ${ }^{5,6}$ The AOF concept seems to be an ideal treatment for a fixed prosthesis with a small number of implants.

Although not as famous as AOF, there is another method by which fixed prosthetic treatment can be achieved with a small number of implants. In this technique, which can be called the all-on-three (AOT) concept, a fixed prosthetic treatment can be performed with three implants placed in the lower jaw. This method, which was realized with special parts of Branemark brand, formerly known as the Branemark Novum protocol, ${ }^{7}$ was applied
Department of Prosthodontics, Akdeniz University, Antalya, Turkey

Corresponding Author: Nurullah Türker, Department of Prosthodontics, Akdeniz University, Antalya, Turkey, Phone: +90 5071513380, e-mail: nurullahturker@hotmail.com

How to cite this article:Türker N. Evaluation of Different Bar Materials in Terms of Stress Transmission in All-on-four and All-on-three Concepts: A Three-dimensional Finite Element Analysis. Int J Experiment Dent Sci 2019;8(2):42-46.

Source of support: Nil

Conflict of interest: None

later without the use of special parts with the designs used in fixed prosthetic treatments on conventional implant. ${ }^{8-11}$

The type of bar material used in treatments where fixed prosthetic treatment is performed with a small number of implants such as AOF and AOT can affect stress transfer. Elastic stresses in the bar may affect the stress from other prosthetic components and to the bone. In order to prolong the life of treatments performed with a small number of implants, it is important to know the ideal bar material that will provide a balanced distribution of stresses caused by chewing forces in bone and prosthetic structures. The aim of this study is to evaluate the effects of materials used in bar construction in the AOF and AOT concepts on stress transmission by three-dimensional (3D) finite element analysis (FEA). 


\section{Materials and Methods}

Two models were designed to simulate the AOF and AOT concepts in the mandible. The mandible model was modeled to include gingiva, trabecular, and cortical bone layers based on an anatomy book. ${ }^{12}$ The cortical bone layer and gingiva were $2 \mathrm{~mm}$ thick. Autodesk Meshmixer (Autodesk Inc.) and Space Claim (Ansys 14.5.7, Ansys Inc.) were used for modeling. Two types of root-shaped bonelevel implants, $10 \mathrm{~mm}$ and $13 \mathrm{~mm}$ long, were modeled based on the physical models that are three times larger than the product catalog of Astra implants. Implant models were multiplied to create three $10 \mathrm{~mm}$ long implants for the AOT concept, two $10 \mathrm{~mm}$ (mesial implants) and two $13 \mathrm{~mm}$ (distal inclined implants) implants for the AOF concept. Implant models were multiplied to create three $10 \mathrm{~mm}$ long implants for the AOT concept, two $10 \mathrm{~mm}$ (mesial implants) and two $13 \mathrm{~mm}$ (distal inclined implants) implants for the AOF concept.

For the AOF concept, mesial implants were placed at the canine teeth position and distal implants were inclined $40^{\circ}$ distally with the neck portions protruding from the second premolar region on both sides. Standard flat abutments were designed for vertically placed implants, and angled abutments and screws were designed for angled placed implants and fixed to the implants. For the AOT concept, one of the implants was placed in the middle of the two incisors in the mandible and the other two implants were placed distally in the first premolar region. The regions where the implant and its parts intersect with the bone and gingiva were evacuated with the "subtract" command. The bar structure was designed on the implants placed in the mandible models and compatible holes were made on the bar in the screw entry regions of both models. The bars were fixed to the implants with screws.

A mandibular denture containing a total of 12 teeth was prepared in the laboratory and scanned with a 3D scanning device. The obtained image was transferred to Autodesk Meshmixer software. The prosthesis model was arranged in this software and adapted to the existing mandible model. Replicated by copy and adapted to the previously created AOF and AOT models. The parts where the prosthetic structure and the bars and screws intersect were evacuated from the prosthetic structure. All parts were assembled in Ansys Design Modeler module (Ansys 14.5.7, Ansys Inc.) (Fig. 1).

Four copies of AOF and AOT models were created. The models were transferred to Ansys Mechanical module, and the material properties and connection types were defined. Table 1 shows the Poisson's ratio and Young modulus values used in the study. ${ }^{13-16}$ Four different bar materials were defined for each treatment concept. All parts were considered homogeneous and isotropic. All connections are provided in the "bonded" type. The mandible was fixed at the muscle attachment sites. A force of $100 \mathrm{~N}$ was applied perpendicular to the long axle from the central fossa of the left first molar tooth and nonlinear FEA was performed. Elastic strain values were obtained from bar and bone tissue.

\section{Results}

\section{Strains in the Bar Structure}

Table 2 shows the strain values observed in the bar structure. Higher strain values were observed in the bar structure of the AOT model. The lowest strain values in both AOT concept and AOF concept were observed in the cobalt-chromium bar structure (Table 2). Figure 2 shows the distributions of strains observed in the bar structure.

\section{Strains Observed in the Bone}

Regardless of the bar material, the overall strain values were highest in the AOF concept, especially in the bone around the implants close to the area where the load was applied (Table 3). Stresses around the implants farther away from the load were lower. In both concepts, the lowest strain values in bone tissue were observed in the models produced with type IV gold alloy bars, while the highest tensile values were observed in models produced with silver-palladium alloy bars. Figure 3 shows the distribution of stresses observed in bone tissue.

\section{Discussion}

Clinical studies are ideal for accurate detection of real situations and possible complications. However, in such studies, it is often not possible to provide cases with the same characteristics and to perform standard tests when various treatment techniques need to be examined comparatively. In such cases, in vitro studies become important. Numerous conditions of in vitro studies can be standardized to test only the desired factors to be studied. The FEA is an ideal experimental method to ensure the standardization of samples and to investigate the effect of only the desired factors by standardizing the clinical situation. ${ }^{17}$
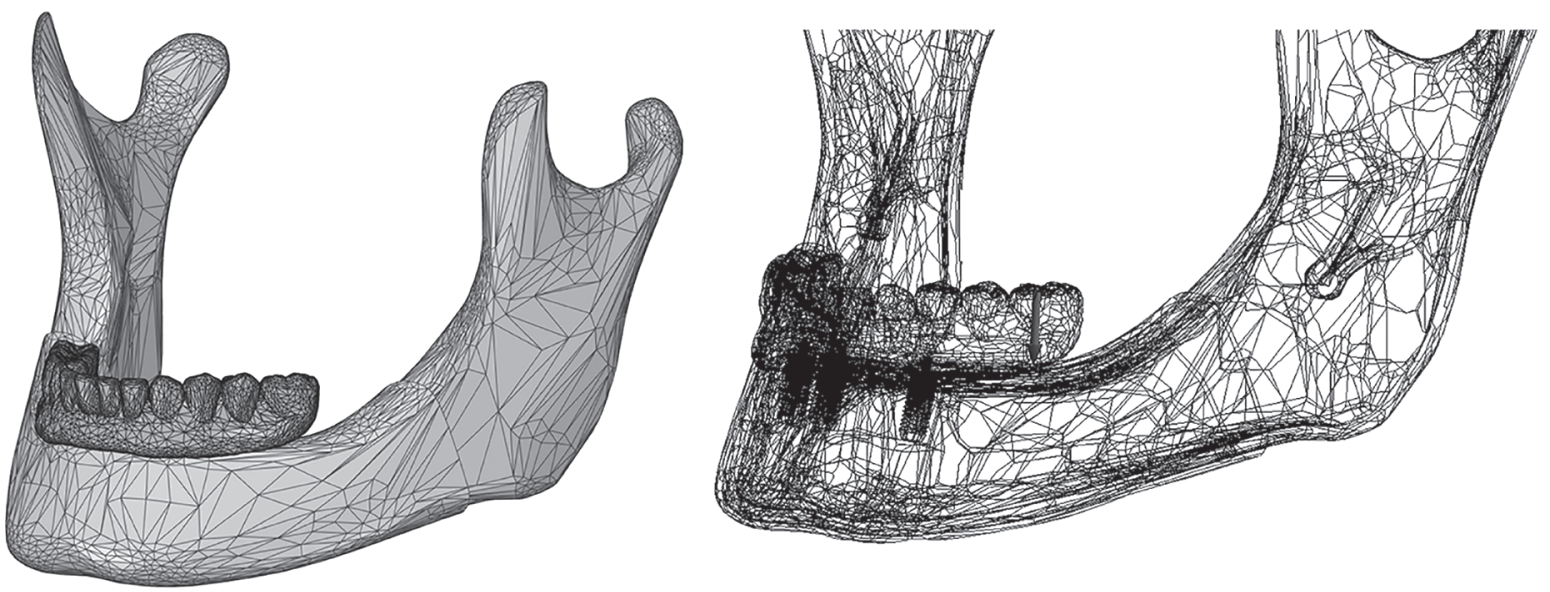

Fig. 1: Three-dimensional image of the studied model 
Table 1: Material properties used in the finite element model

\begin{tabular}{llcl}
\hline Component & Material & $\begin{array}{l}\text { Elastic modulus } \\
\text { (GPa) }\end{array}$ & $\begin{array}{l}\text { Poisson's } \\
\text { ratio }\end{array}$ \\
\hline Cortical bone & - & 13.70 & 0.30 \\
Trabecular bone & - & 1.37 & 0.30 \\
Base and teeth & Acrylic & 8.30 & 0.28 \\
Bar & Titanium & 115.00 & 0.35 \\
Implant and components & Titanium & 115.00 & 0.35 \\
\hline
\end{tabular}

Table 2: Strain values observed in the bar structure

\begin{tabular}{lll}
\hline All-on-three & Type IV gold alloy & 0.0012 \\
& Silver-palladium alloy & 0.001 \\
& Commercially pure titanium & 0.0011 \\
& Cobalt-chromium & 0.00063 \\
All-on-four & Type IV gold alloy & 0.00078 \\
& Silver-palladium alloy & 0.00071 \\
& Commercially pure titanium & 0.00061 \\
& Cobalt-chromium & 0.0005 \\
\hline
\end{tabular}

In the present study, AOF and AOT concepts were designed according to the clinical standards, and the effects of various bar materials on strain distribution were examined by standardizing all other factors. The findings of the study showed that the material with the lowest strain in the bar structure and the material causing the lowest strain in the bone tissue were not the same. Strains in the bar structure may cause mechanical complications in the prosthetic structure and upper parts of the implant. ${ }^{4}$ In order to minimize such situations, it appears that cobalt-chromium material should be preferred in bar construction. Strains in the bone can cause bone resorption and loss of implants in the long-term. ${ }^{18}$ Mechanical complications are easier to overcome than to completely remaking the treatment. Therefore, if type IV alloy material is preferred in bar construction, it can be said that the survival time for AOF and AOT concept can be extended and higher success can be achieved in the long-term.

Few studies in the literature examine stresses in bar materials. Caetano et al. and Spazzin et al. ${ }^{3,19}$ reported that the lowest stress values were found in type IV gold alloy bars and the highest values were found in cobalt-chromium material bars. Abreu et al. ${ }^{4}$ reported that the higher the hardness of the bar material, the
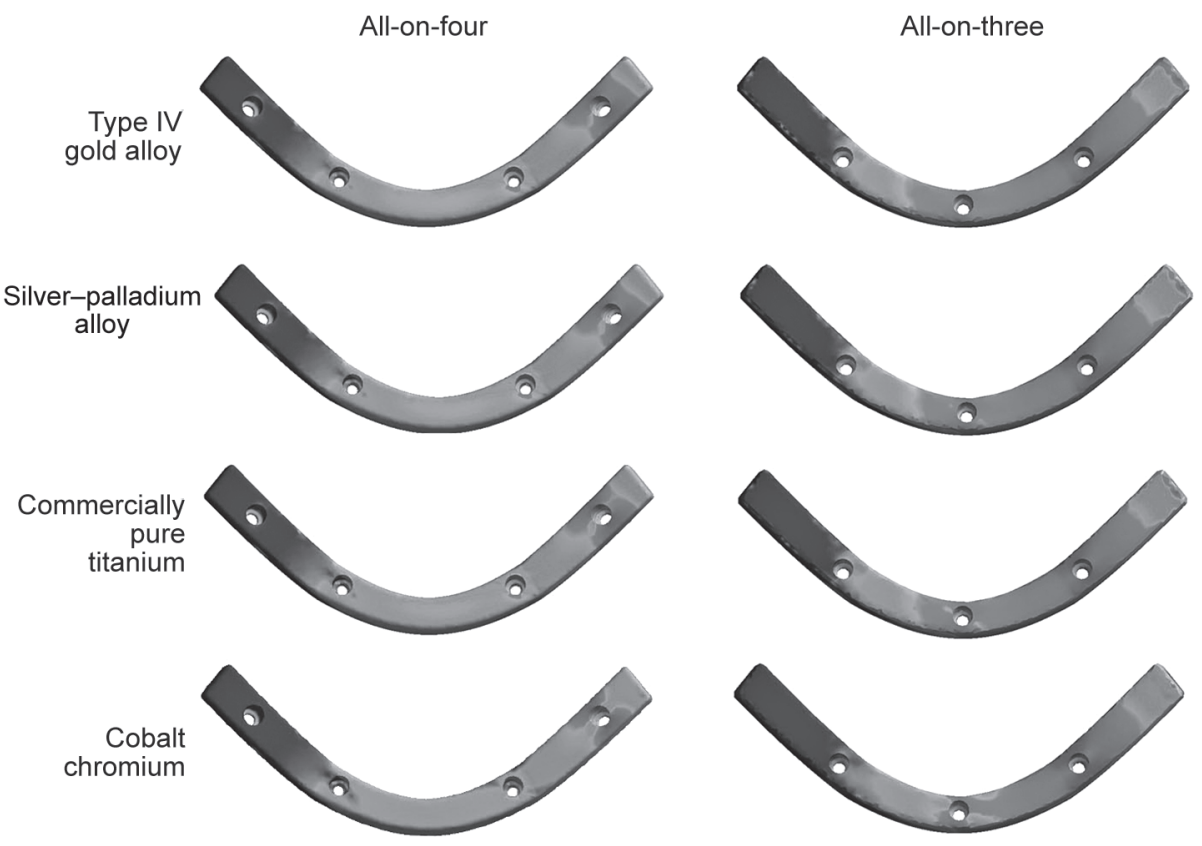

Fig. 2: Strain distributions in bar models

Table 3: Strain values observed in the bone

\begin{tabular}{|c|c|c|c|c|c|c|}
\hline & & & \multicolumn{2}{|l|}{ Right } & Middle & Left \\
\hline \multirow[t]{5}{*}{ All-on-three } & Type IV gold alloy & & \multicolumn{2}{|c|}{$5.11 \times 10^{-5}$} & $2.38 \times 10^{-4}$ & $2.81 \times 10^{-4}$ \\
\hline & Silver-palladium allo & & \multicolumn{2}{|c|}{$3.40 \times 10^{-5}$} & $2.50 \times 10^{-4}$ & $2.97 \times 10^{-4}$ \\
\hline & Commercially pure ti & anium & \multicolumn{2}{|c|}{$5.20 \times 10^{-5}$} & $2.54 \times 10^{-4}$ & $2.83 \times 10^{-4}$ \\
\hline & Cobalt-chromium & & \multicolumn{2}{|c|}{$4.10 \times 10^{-5}$} & $2.56 \times 10^{-4}$ & $2.95 \times 10^{-4}$ \\
\hline & & \multicolumn{2}{|c|}{ Right posterior } & Right anterio & Left anterior & Left posterior \\
\hline \multirow[t]{4}{*}{ All-on-four } & Type IV gold alloy & \multicolumn{2}{|c|}{$2.30 \times 10^{-4}$} & $1.34 \times 10^{-4}$ & $1.91 \times 10^{-4}$ & $8.77 \times 10^{-4}$ \\
\hline & Silver-palladium alloy & \multicolumn{2}{|c|}{$6.00 \times 10^{-5}$} & $5.10 \times 10^{-5}$ & $3.12 \times 10^{-4}$ & $1.30 \times 10^{-3}$ \\
\hline & $\begin{array}{l}\text { Commercially pure } \\
\text { titanium }\end{array}$ & \multicolumn{2}{|c|}{$2.40 \times 10^{-4}$} & $5.10 \times 10^{-5}$ & $1.25 \times 10^{-4}$ & $1.23 \times 10^{-3}$ \\
\hline & Cobalt-chromium & \multicolumn{2}{|c|}{$2.42 \times 10^{-4}$} & $5.50 \times 10^{-5}$ & $1.21 \times 10^{-4}$ & $1.16 \times 10^{-3}$ \\
\hline
\end{tabular}



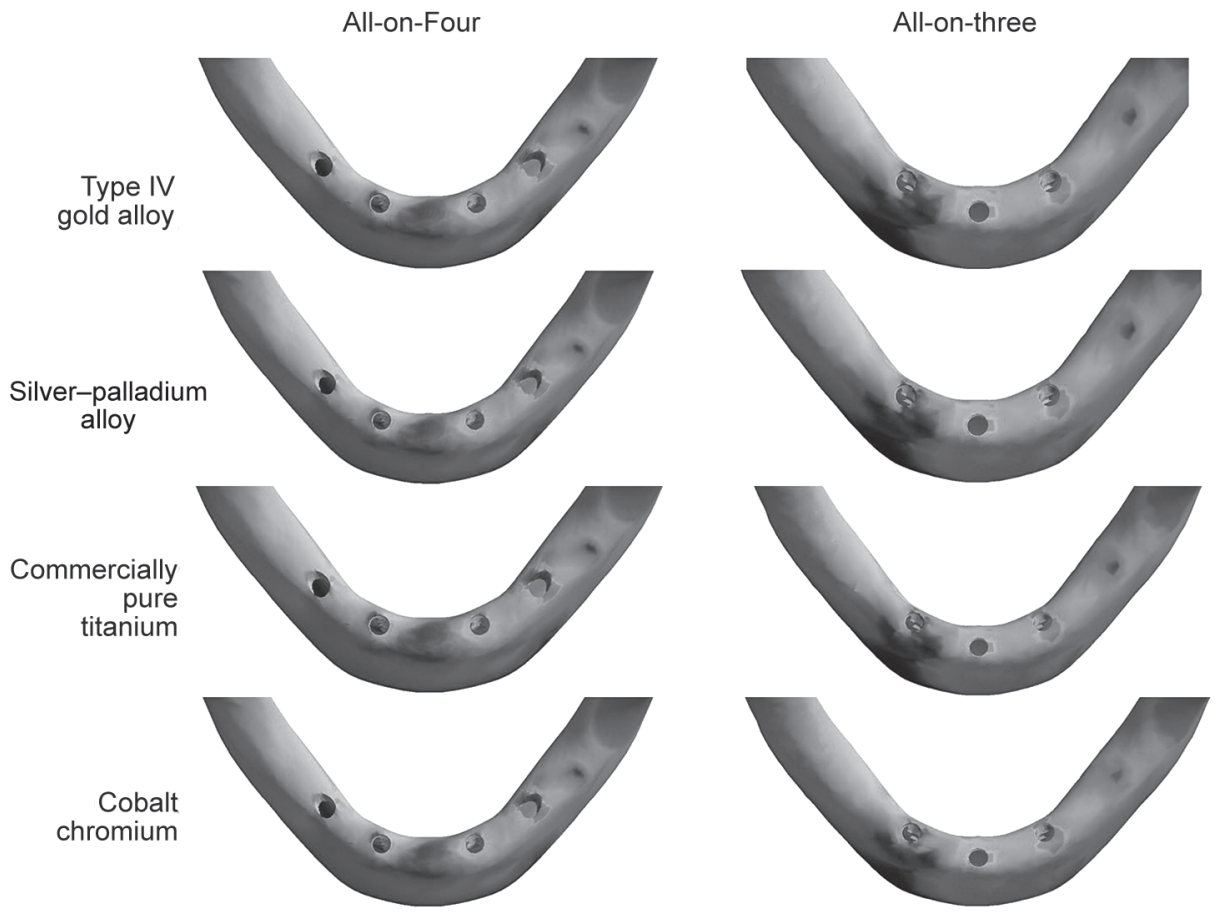

Fig. 3: Strain distributions in the bone

higher the stress. In the present study, the highest strain values were observed in cobalt-chromium bar structure and the lowest strain values were observed in type IV gold alloy bar structure. As the material stiffness increased, the strain values decreased. This difference may be due to factors such as the design of the bar and the position of the applied force. Previous studies have examined the stresses of bars in removable prostheses containing bars on two implants..$^{3,4,19}$ Bar design is quite different in AOF and AOT concepts. The effects of bar design on stress distribution should be investigated in the future studies.

Inadequate amount of bone, inadequate anatomical and physiological condition, and economic reasons force dentists to treatment concepts containing less number and specially positioned implants. These are the main factors in the emergence of AOF and AOT concepts. Many studies compare the AOF concept with treatments involving a larger number of implants. ${ }^{20,21}$ However, there are no enough studies comparing AOF concept with AOT concept. It is important to know the effect of factors such as occlusion, prosthetic material, bar material, cantilever length, and the exact position of the implants in both concepts to choose the ideal treatment type. Lower bone quality in the maxilla usually requires the use of more implants compared to the mandible. Although some clinicians have also applied on the maxilla, the AOT concept was developed for the mandible with a denser bone structure. ${ }^{7}$ For this reason, the treatments applied to the mandible were compared in the present study.

In the present study, the force was applied from the cantilever area, and in the AOT concept the cantilever length is longer than the AOF concept. A longer cantilever means more stress. ${ }^{22,23}$ Considering simply, stresses can be expected to occur more in the AOT concept than in the AOF concept. In this study, it is remarkable that the highest strain values in the bone were observed in the bone around the distal implant in AOF concept. Several studies have shown that higher stress values occur around the distal implant in the AOF concept. ${ }^{21,24}$ Regardless of the bar material, the formation of more stress on the bone compared to that in the AOT concept is important for requestioning the use of inclined implants in the posterior region. The use of vertical implants instead of inclined implants can reduce stress to the bone, and thus the use of a small number of implants may be more advantageous. Some researchers have inclined the posterior implants distally in the AOT concept. ${ }^{8,9}$ The effects of such an application in stress distribution should be investigated.

Significant bone loss may occur if the implants are lost. ${ }^{25}$ In such a case, bone healing and ensuring a new treatment may require long-term and complicated applications. Treatments such as AOF and AOT are mostly used in elderly individuals and individuals with resorbed crest to benefit from the remaining bone tissue. ${ }^{26}$ Therefore, on these treatments, any factor that may affect bone resorption and implant loss should be evaluated in detail. In this study, it has been shown that the material to be preferred in the bar structure is effective on the stresses in the bone tissue. The effect of bar-related and many other factors on stress values in AOF and AOT concepts should be investigated in the future in vivo and in vitro studies.

\section{Conclusion}

Within the limits of this study, the following results were obtained:

- In the AOF and AOT techniques, the type of bar material affects the strains in the bar structure and bone tissue.

- The material with the lowest strain observed in the bar material and the material causing the lowest strain in the bone tissue are not the same. Type IV gold alloy can be preferred for long-life treatments. 
- In the present study, different findings were obtained about the strain values of bar materials from previous studies. The design of the bar may affect material-dependent strain values.

\section{Clinical Significance}

In the AOF and AOT concepts, which are fixed prosthetic treatment options with a less number of implants, the type of bar material used is important for the success of the treatment.

\section{References}

1. Jofre J, Cendoya P, Muñoz P. Effect of splinting mini-implants on marginal bone loss: a biomechanical model and clinical randomized study with mandibular overdentures. Int J Oral Maxillofac Implants 2010;25(6):1137-1144.

2. Tokuhisa M, Matsushita Y, Koyano K. In vitro study of a mandibular implant overdenture retained with ball, magnet, or bar attachments: comparison of load transfer and denture stability. Int J Prosthodont 2003;16:251-258

3. Caetano CR, Mesquita MF, Consani RLX, et al. Overdenture retaining bar stress distribution: a finite-element analysis. Acta Odontol Scand 2015:73(4):274-279. DOI: 10.3109/00016357.2014.923111.

4. Abreu RT, Spazzin AO, Noritomi PY, et al. Influence of material of overdenture-retaining bar with vertical misfit on three-dimensional stress distribution. J Prosthodont 2010;19(6):425-431. DOI: 10.1111/j.1532-849X.2010.00612.x

5. Malo P, de Araújo Nobre M, Lopes A, et al. A longitudinal study of the survival of all-on-4 implants in the mandible with up to 10 years of follow-up. J Am Dent Assoc 2011;142(3):310-320. DOI: 10.14219/jada. archive.2011.0170.

6. Maló P, de Araújo Nobre M, Lopes A, et al. "All-on-4" immediatefunction concept for completely edentulous maxillae: a clinical report on the medium ( 3 years) and long-term (5 years) outcomes. Clin Implant Dent Relat Res 2012;14(Suppl 1):e139-e150. DOI: 10.1111/j.1708-8208.2011.00395.x.

7. Brånemark PI, Engstrand P, Öhrnell LO, et al. Brånemark Novum : a new treatment concept for rehabilitation of the edentulous mandible. Preliminary results from a prospective clinical follow-up study. Clin Implant Dent Relat Res 1999;1(1):2-16. DOI: 10.1111/j.1708-8208.1999. tb00086.x.

8. Oliva J, Oliva X, Oliva JD. All-on-three delayed implant loading concept for the completely edentulous maxilla and mandible: a retrospective 5-year follow-up study. Int J Oral Maxillofac Implants 2012;27:1585-1592.

9. Ayna M, Sagheb K, Gutwald R, et al. A clinical study on the 6-year outcomes of immediately loaded three implants for completely edentulous mandibles: "the all-on-3 concept". Odontology 2019; 1-10. DOI: 10.1007/s10266-019-00440-8.

10. Hatano N, Yamaguchi M, Yaita T, et al. New approach for immediate prosthetic rehabilitation of the edentulous mandible with three implants: a retrospective study. Clin Oral Implants 2011;22(11): 1265-1269. DOI: 10.1111/j.1600-0501.2010.02101.x.

11. Beresford D, Klineberg I. A within-subject comparison of patient satisfaction and quality of life between a two-implant overdenture and a three-implant-supported fixed dental prosthesis in the mandible. Int J Oral Maxillofac 2018;33:1374-1382. DOI: 10.11607/ jomi.6666.

12. Baker EW, Schulte E, Schumacher U. Head and neck anatomy for dental medicine, 2nd ed. New York: Thieme; 2010. pp. 2-22.

13. Archangelo CM, Rocha EP, Pereira JA, et al. Periodontal ligament influence on the stress distribution in a removable partial denture supported by implant: a finite element analysis. J Appl Oral Sci 2012;20(3):362-368. DOI: 10.1590/S1678-77572012000300012.

14. Mehdi G, Belarbi A, Mansouri B, et al. Numerical study of effect of elastomeric stress absorbers on stress reduction in bone-dental implant interface. J Appl Oral Sci 2015;23(1):87-93. DOI: 10.1590/1678775720140086.

15. Ozan O, Ramoglu S. Effect of implant height differences on different attachment types and peri-implant bone in mandibular twoimplant Overdentures: 3D finite element study. J Oral Implantol 2015;41(3):e50-e59. DOI: 10.1563/AAID-JOI-D-13-00239.

16. Silva GC, Mendonca JA, Lopes LR, et al. Stress patterns on implants in prostheses supported by four or six implants: a three-dimensional finite element analysis. Int J Oral Maxillofac Implants 2010;25(2): 239-246.

17. Trivedi S. Finite element analysis: A boon to dentistry. J Oral Biol Craniofac Res 2014;4(3):200-203. DOI: 10.1016/j.jobcr.2014.11.008.

18. Isidor F. Influence of forces on peri-implant bone. Clin Oral Implants 2006;17(Suppl 1):8-18. DOI: 10.1111/j.1600-0501.2006.01360.x.

19. Spazzin AO, dos Santos MBF, Sobrinho LC, et al. Effects of horizontal misfit and bar framework material on the stress distribution of an overdenture-retaining bar system: a 3D finite element analysis. J Prosthodont 2011;20(7):517-522. DOI: 10.1111/j.1532849X.2011.00759.x.

20. Fazi G, Tellini $S$, Vangi $D$, et al. Three-dimensional finite element analysis of different implant configurations for a mandibular fixed prosthesis. Int J Oral Maxillofac Implants 2011;26(4):752-759.

21. Almeida EO, Rocha EP, Júnior ACF, et al. Tilted and short implants supporting fixed prosthesis in an atrophic maxilla: a 3D-FEA biomechanical evaluation. Clin Implant Dent Relat Res 2015;17: e332-e342. DOI: 10.1111/cid.12129.

22. De Medeiros RA, Goiato MC, Pesqueira AA, et al. Stress distribution in an implant-supported mandibular complete denture using different cantilever lengths and occlusal coating materials. Implant Dent 2017;26:106-111. DOI: 10.1097/ID.0000000000000534.

23. Ebadian B, Mosharraf R, Khodaeian N. Effect of cantilever length on stress distribution around implants in mandibular overdentures supported by two and three implants. Eur J Dent 2016;10:333-339. DOI: 10.4103/1305-7456.184152.

24. Türker N, Büyükkaplan US, Sadowsky SJ, et al. Finite element stress analysis of applied forces to implants and supporting tissues using the "All-on-Four" concept with different occlusal schemes. J Prosthodont 2019;28(2):185-194.

25. Vervaeke S, Collaert B, Cosyn J, et al. A multifactorial analysis to identify predictors of implant failure and peri-implant bone loss. Clin Implant Dent Relat Res 2015;17(Suppl 1):e298-e307. DOI: 10.1111/ cid.12149.

26. Soto-Peñaloza D, Zaragozí-Alonso R, Peñarrocha-Diago $M$, et al. The all-on-four treatment concept: systematic review. J Clin Exp Dent 2017:9(3):474-478. DOI: 10.4317/jced.53613. 